Article

\title{
Economic Evaluation of Smart PV Inverters with a Three-Operation-Phase Watt-Var Control Scheme for Enhancing PV Penetration in Distribution Systems in Taiwan
}

\author{
Shih-Chieh Hsieh ${ }^{1, *}$, Yih-Der Lee ${ }^{2}$ and Yung-Ruei Chang ${ }^{2}$ \\ 1 Department of Electrical Engineering, I-Shou University, Kaohsiung City 84001, Taiwan \\ 2 Institute of Nuclear Energy Research, Taoyuan City 32546, Taiwan; ydlee@iner.gov.tw (Y.-D.L.); \\ raymond@iner.gov.tw (Y.-R.C.) \\ * Correspondence: hsiehten@isu.edu.tw; Tel.: +886-7-657-7711
}

Received: 20 May 2018; Accepted: 7 June 2018; Published: 13 June 2018

\begin{abstract}
The paper presents an economic evaluation, including a cost-benefit analysis and a sensitivity analysis, of smart photovoltaic (PV) inverters with a novel Watt-Var control scheme for enhancing PV penetration in distribution systems in Taiwan. The novel Watt-Var control scheme with three operation phases is utilized to avoid the voltage violation problem during peak solar irradiation period and increase the PV real power injection, and thus can get higher PV penetration in distribution systems. To evaluate the benefit and cost of the PV investment project, the annual revenue of PV power sales, the initial capital investment cost for a PV project with or without a smart inverter, and the operating and maintenance (O\&M) cost are taken into account. The paper demonstrates the analyses of net present value (NPV) and benefit-cost ratio (BCR) for the PV project. In addition, the paper also presents a sensitivity analysis to deal with the project uncertainty with respect to some affecting parameters. The analyzing results show that, under the feed-in tariffs (FITs) policy, with proper selection of PV and smart inverter capacities, the investment can be profitable, and the smart PV inverter can greatly enhance the PV penetration in distribution systems in Taiwan. These results can provide some useful information for making policy to encourage investment in solar PV industry.
\end{abstract}

Keywords: photovoltaic (PV) penetration enhancement; smart PV inverter; Watt-Var control; cost-benefit analysis; net present value (NPV); benefit-cost ratio (BCR); sensitivity analysis

\section{Introduction}

Governments of all countries in the world, including Taiwan, are intensively promoting renewable energy to reduce the dependence on petrochemical energy and the impact on the global environment. Taiwan has planned to increase the share of renewable energy generation capacity up to $20 \%$ by the year 2025, in which the solar photovoltaic (PV) installed capacity is planned to reach 20 GW. Specifically, the rooftop and ground-mounted systems will account for $3 \mathrm{GW}$ and $17 \mathrm{GW}$, respectively. Energy Bureau of the Ministry of Economic Affairs in Taiwan also announced the Solar PV Two-Year Promotion Project [1] to increase 1.52 GW of installed capacity between July 2016 and June 2018. To install a PV system in Taipower distribution systems, the voltage variation percentage at the point of common coupling (PCC) should not exceed 2.5\% [2]. This voltage limitation would impose an upper limit on the injection power from the PV system and the hosting capacity for renewable generation (RG).

To progress towards the development of sustainable energy, a review on the current status, applications, developmental barriers, and prospects of solar photovoltaic systems in India was briefed 
in [3]. The study also mentioned the renewable energy policies and some recommendations. To speed up renewable energy development, policy experience in many countries has shown that mandatory buy-back policies with feed-in tariffs (FITs) that specify a favorable purchase price for renewable energy are one of the most effective incentives [4]. In Taiwan, the FIT policy is mainly applied.

For successful operation of a grid-tied renewable energy system, lots of works on power inverters have been proposed and investigated in the literature. A survey of power-electronic systems for the grid integration of renewable energy sources was presented in [5] and a comparison with different technologies and wide range of power ratings for PV systems was found in [6]. To avoid the voltage violation problem caused by large intermittent injection of RGs, many invert-based techniques [7-9] allowing the distributed generations to absorb reactive power from the power system were proposed. In addition, to mitigate the overvoltage problem and enhance the PV penetration in distribution system, a distribution static compensator (DSTATCOM) application was proposed in [10] and a PV inverter control scheme with battery energy storage systems (BESS) was presented in [11]. As shown in [12], the smart PV inverter can enhance the maximum power generation limit, provide power output with fixed power factor, intelligently control the voltage variation, and conduct real power adjustment and reactive power compensation. Recently, a smart PV inverter with Volt-Var droop control method [13] for distributed voltage regulation was tested and analyzed under Maui Advanced Solar Initiative Project in Hawaii. However, the Vol-Var droop control curve is piecewise linear and the optimal real power output cannot be guaranteed. Recently, a coordination method of smart PV inverters and the novel Watt-Var control scheme with three operation phases [14] has been proposed to mitigate voltage violation for load transfer between distribution feeders with high penetration of PV installation under National Energy (NEP) II Project in Taiwan. The novel three-operation-phase Watt-Var control scheme can fully utilize PV's capacity to keep PV's real power output as high as possible. Thus, this paper will then present the novel Watt-Var control scheme to improve the PV penetration in the distribution system.

To provide more information for investors and governments to make better decisions or policies for the PV industry, the economic feasibility of residential energy storage combined with PV panels in Italy [15] considering subsidies, and an economic evaluation of the hybrid enhancing scheme with DSTATCOM and active power curtailment for PV penetration in Taipower distribution systems [16] considering FITs, were presented. In this paper, a cost-benefit analysis and a sensitivity analysis considering FITs for our novel Watt-Var control scheme [14] with three operation phases to enhance PV penetration in distribution systems in Taiwan will then be presented.

The paper is organized first to utilize the smart PV inverter with novel Watt-Var control function to maximize the PV real power injected into the distribution feeder, so that the voltage variation rate at the PCC shall not exceed $2.5 \%$. The paper then utilizes the Open Distribution System Simulator (OpenDSS) [17] to simulate and find the maximum real power injection and associated capacity of the PV generation system allowed to integrate into the distribution feeder by a bisection search. The whole year's load data, solar irradiation data, and temperature data are applied to find the real power produced by the PV system, the real power injected into the feeder, and the curtailment of PV real power. The annual revenue of PV power sales, the initial capital investment cost for a PV project with or without a smart inverter, and the operating and maintenance (O\&M) cost are taken into account. The paper then presents a cost-benefit analysis [18] (using indicators net present value (NPV) $[15,16]$ and net present value (BCR) [16]) and a sensitivity analysis $[16,18]$ for the cases with and without power factor control function. Finally, some concluding remarks are presented. 


\section{Materials and Methods}

\subsection{Real and Reactive Power Control Scheme of Smart PV Inverters}

When the PV's real power injection into the distribution system results in a voltage variation percentage of more than $2.5 \%$ at the PCC, the use of a smart PV inverter with Watt-Var control scheme can reduce the voltage variation. The voltage variation percentage at the PCC is defined as

$$
\Delta \mathrm{V} \%=\frac{\left|V_{\text {withPV }}-V_{\text {withoutPV }}\right|}{V_{\text {without } P V}} \times 100 \%,
$$

where $V_{\text {withPV }}$ and $V_{\text {withoutPV }}$ are the voltage magnitudes at the PCC with and without PV system, respectively. The Watt-Var control scheme [9] investigated in the paper is presented in Figure 1, which comprises three operation phases.

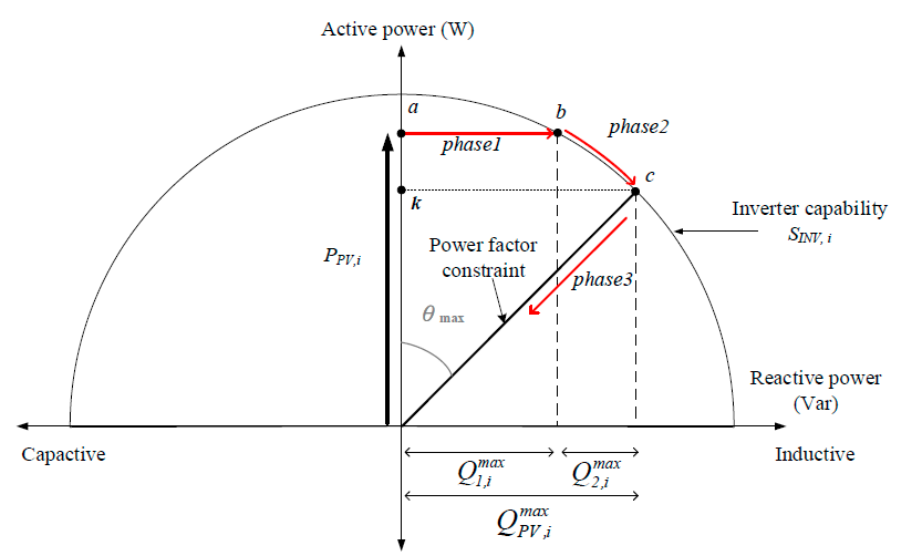

Figure 1. The Watt-Var control scheme of a smart PV inverter.

\subsubsection{Phase 1: Fix PV Real Power Output and Dispatch Reactive Power}

When the maximal-power-point-tracking real power output of the PV panel results in PV-connected bus voltage higher than the maximum allowable voltage, to fully utilize the smart PV inverter's capacity, the reactive power compensation control is implemented without changing the real power output when the PV inverter still has enough capacity. To solve the problem of voltage variation percentage over $2.5 \%$, the inductive reactive compensation at the PV-connected bus of the feeder is increased. The maximum allowable reactive power compensation of the inverter at this phase can be calculated by Label (2):

$$
Q_{j}^{\max }=\left\{\begin{array}{ll}
\sqrt{S_{I N V, j}^{2}-P_{P V, j}^{2}}, & P_{P V, j}>S_{I N V, j} \cos \theta_{\max } \\
P_{I N V, j} \cdot \tan \theta_{\max }, & P_{P V, j} \leq S_{I N V, j} \cos \theta_{\max }
\end{array} .\right.
$$

If the value of reactive power compensation exceeds the limit, then set it at the limit. When the PV-connected bus voltage is lower than or equal to the maximum allowable voltage, the Watt-Var control scheme will be terminated. If the inverter reaches the limit of reactive power compensation and the voltage variation still exceeds the limit, the Phase 2 control step will be started.

2.1.2. Phase 2: Fix Inverter at Rated Capacity, Increase Reactive Power Output, and Reduce Real Power Output

When the PV inverter has reached its capacity limit, the continuously increased reactive power compensation will result in a decrease of the real power output. At this phase, the maximum amount of reactive power compensation equals $Q_{2}^{\max }=S \times \sin \theta_{\max }-Q_{1}^{\max }$. 
2.1.3. Phase 3: Fix Inverter at the Power Factor Limit and Reduce the Real and Reactive Power Outputs

When the PV inverter operating point reaches the power factor limit, fix the power factor at $\cos \theta_{\max }$ and reduce the real power and reactive power outputs accordingly. At this point, the ratio of PV reactive power reduction to real power reduction is equal to $\tan \theta_{\max }$.

\subsection{Determining the Maximum Real Power Injection and Capacity of PV System with a Smart Inverter}

As shown in Figure 2, the decision-making process of maximum real power injection and capacity of PV system with a smart inverter can be divided into the following four stages:

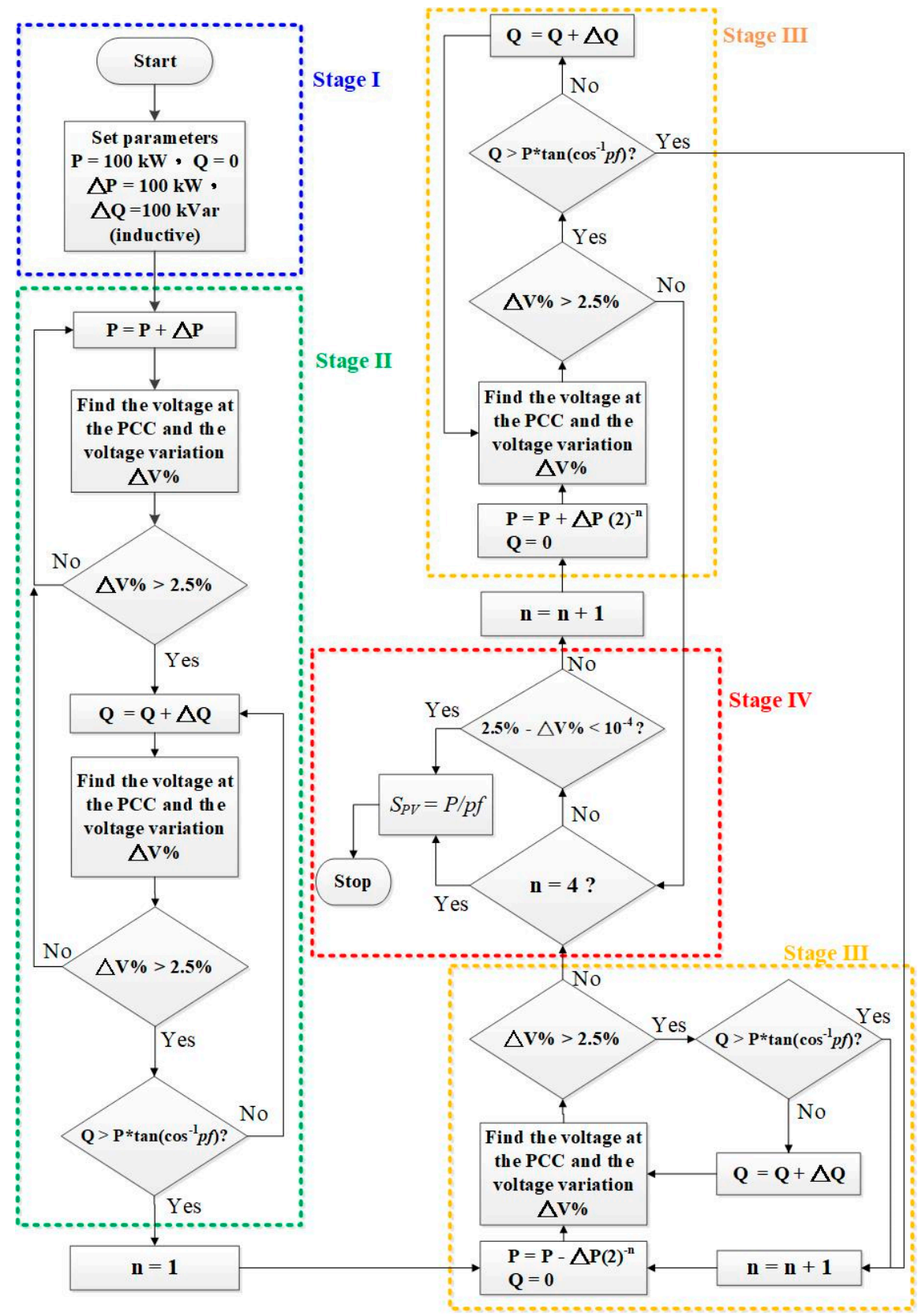

Figure 2. Flow chart to determine the maximum real power injection and capacity of a PV system with a smart inverter. 
- Stage I: Set Parameters

Setup the parameters required in the OpenDSS software (Version 8.1.1, Electric Power Research Institute, Palo Alto, CA, USA), such as voltage levels, the standard value, phase, angle, frequency, the type and length of the wire connection on the bus, load, capacitor, power factor, etc.

- Stage II: Increase Real Power and Compensate Reactive Power

When the real power injection is increased too much, the voltage variation percentage may become greater than $2.5 \%$. Then, to reduce the voltage variation, the inductive reactive power $\mathrm{Q}$ can be added. When the inverter still has enough $Q$ available, it will fix the real power and only compensate the inductive reactive power to reduce $\Delta \mathrm{V}$. If the $\mathrm{Q}$ value reaches the maximum allowable value $Q_{\max }=P \times \tan \left(\cos ^{-1} p f\right)$ where $p f$ is the power factor control limit of the inverter and the $\Delta \mathrm{V} \%$ is still greater than $2.5 \%$, then it is necessary to cut down the real power output and step into Stage III.

- Stage III: Search Maximum Real Power Injection by Bisection

Inside the dotted yellow line in the bottom of Figure 2, if the maximum allowable reactive power $Q_{\max }$ is reached and the voltage variation is still more than the limit of $2.5 \%$, then the real power reduction, $\Delta \mathrm{P}\left(\frac{1}{2}\right)^{n}$. will be carried out to reduce the voltage variation, where $n=1$ for the first-time decrease in $\mathrm{P}$. When the voltage variation percentage is below the limit of $2.5 \%$, the real power increment, $\Delta \mathrm{P}\left(\frac{1}{2}\right)^{n}$, will be carried out to increase the voltage variation. Such process is repeated before reaching a near maximum point of the real power injection.

- Stage IV: Check Stopping Criterion and Calculate the Maximum PV Capacity

1. Check if $n$ is equal to 4 . When $n=4$, the increase or decrease of $P$ would be small; if $n$ continues to increase, then the impact of $\Delta \mathrm{V}$ can be neglected. Then, we can stop the procedure and calculate a near maximum PV capacity $S_{P V}=P / p f$, or it can be stopped by the following criterion.

2. When $n<4$ and $2.5 \%-\Delta \mathrm{V} \%<10^{-4}$, the error tolerance is taken to be acceptable and the procedure can be stopped. A near maximum PV capacity can then be obtained.

\subsection{Indicators Used in the Cost-Benefit Analysis}

In this paper, we apply two common cost-benefit analysis indicators [18], Net Present Value (NPV) and the Benefit-Cost Ratio (BCR) as shown in Labels (3) and (4), in order to investigate the projects with or without smart PV inverters. When the NPV is greater than zero or the BCR is bigger than one, the project will make a profit. Otherwise, the project should be discarded. In addition, the larger the indicators, the higher the profit:

$$
\begin{gathered}
N P V=\sum_{n=0}^{N} \frac{B_{n}-C_{n}}{(1+i)^{n}} \\
B C R=\left[\sum_{n=0}^{N} \frac{B_{n}}{(1+i)^{n}}\right] /\left[\sum_{n=0}^{N} \frac{C_{n}}{(1+i)^{n}}\right],
\end{gathered}
$$

where

$B_{n}=$ Benefit at year $n$,

$C_{n}=$ Cost at year $n$,

$N=$ Project life (year),

$i=$ Discount or interest rate.

Before making investment in a solar PV project, the investors need to evaluate whether the project can make them a profit. The benefit considered here is the internality only for PV investors' personal benefit, i.e., the revenue of PV power sales over the PV system's life cycle and the externality is not 
considered in the paper. The cost includes the initial investment cost for a PV system with a normal or smart inverter and its O\&M cost.

\subsection{Test System and Parameter Setting}

The test system analyzed in this paper is an $11.4-\mathrm{kV}$ distribution feeder in a Taipower system, and a PV system is connected at Bus 9, as shown in Figure 3 [16]. The parameters and load data in [16] showing one day in summer with different hourly loads are used in this paper. The voltage variation at Bus 9 with connected PV system is the most devastated. Therefore, Bus 9 is selected for maximum grid-connected analysis of distributed generation and it must comply with the voltage variation regulation $(\Delta \mathrm{V} \%<2.5 \%)$.

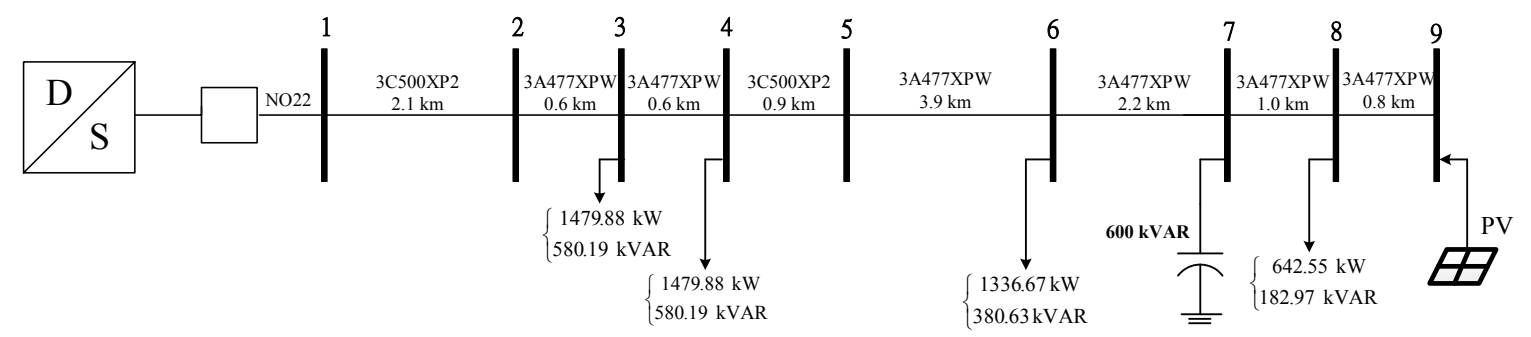

Figure 3. One-line diagram of an $11.4 \mathrm{kV}$ distribution feeder in a Taipower system.

To speed up the Million Solar Rooftop PV Project in Taiwan, the PV power purchase price or FIT rate was set at NT\$4.8845/kWh [19]. The average PV price of $1 \mathrm{kWp}$ is calculated on the basis of the quoted price of Solar Choice, and the average PV panel price of $100 \mathrm{kWp}$ is converted into US\$138,270, or NT\$ 51,850 per kWp [20]. According to the Western Power Industry Group (WEIL) Group's propose that the smart inverter price is about US $\$ 150 / \mathrm{kWp}$ higher than that of a normal inverter, the $1-\mathrm{kWp}$ PV unit cost with smart inverter is about NT\$ 56,350 [21]. The cost parameters used for economic evaluation are then listed in Table 1.

Table 1. Cost parameters used for economic evaluation; O\&M: operating and maintenance; FIT: feedin tariff.

\begin{tabular}{cc}
\hline Cost Parameters & Numerical Value \\
\hline PV Installation Cost with normal inverter (NT\$/kWp) & 51,850 \\
PV Installation Cost with smart inverter (NT\$/kWp) & 56,350 \\
PV Performance De-rating Rate (\%/year) & 1.4 \\
O\&M Cost (\%/year) & 0.5 \\
Economic Life (years) & 20 \\
PV Power Purchase Price or FIT rate (NT\$/kWh) & 4.8845 \\
Discount Rate (\%/year) & 3 \\
\hline
\end{tabular}

\section{Simulation Results}

In this paper, the Open Distribution System Simulator (OpenDSS) developed by Electric Power Research Institute (EPRI) [17] is utilized for modeling and simulation. The three-phase load flow analysis of the study feeder is performed to solve the voltage magnitude at the PCC point.

\subsection{Annual PV Real Power Generation, Injection, and Curtailment}

To estimate the annual generation of power by the PV system for economic evaluation, the local hourly weather data collected by the Central Weather Bureau of Taiwan over a one-year period is used. By a statistic regression analysis, the maximal real power output $P_{\text {mrpo }}(\mathrm{W})$ of a $1-\mathrm{kWp}$ PV module is formulated as follows [16]:

$$
P_{\text {mrpo }}=-11.18+0.834 G+0.734 T-1.955 \times 10^{-3} G \cdot T,
$$


where $G$ and $T$ are the solar irradiation in $\mathrm{W} / \mathrm{m}^{2}$ and the surface temperature of PV panels in ${ }^{\circ} \mathrm{C}$, respectively. Accordingly, the annual PV real power generation for different PV capacities can be plotted in Figure 4.

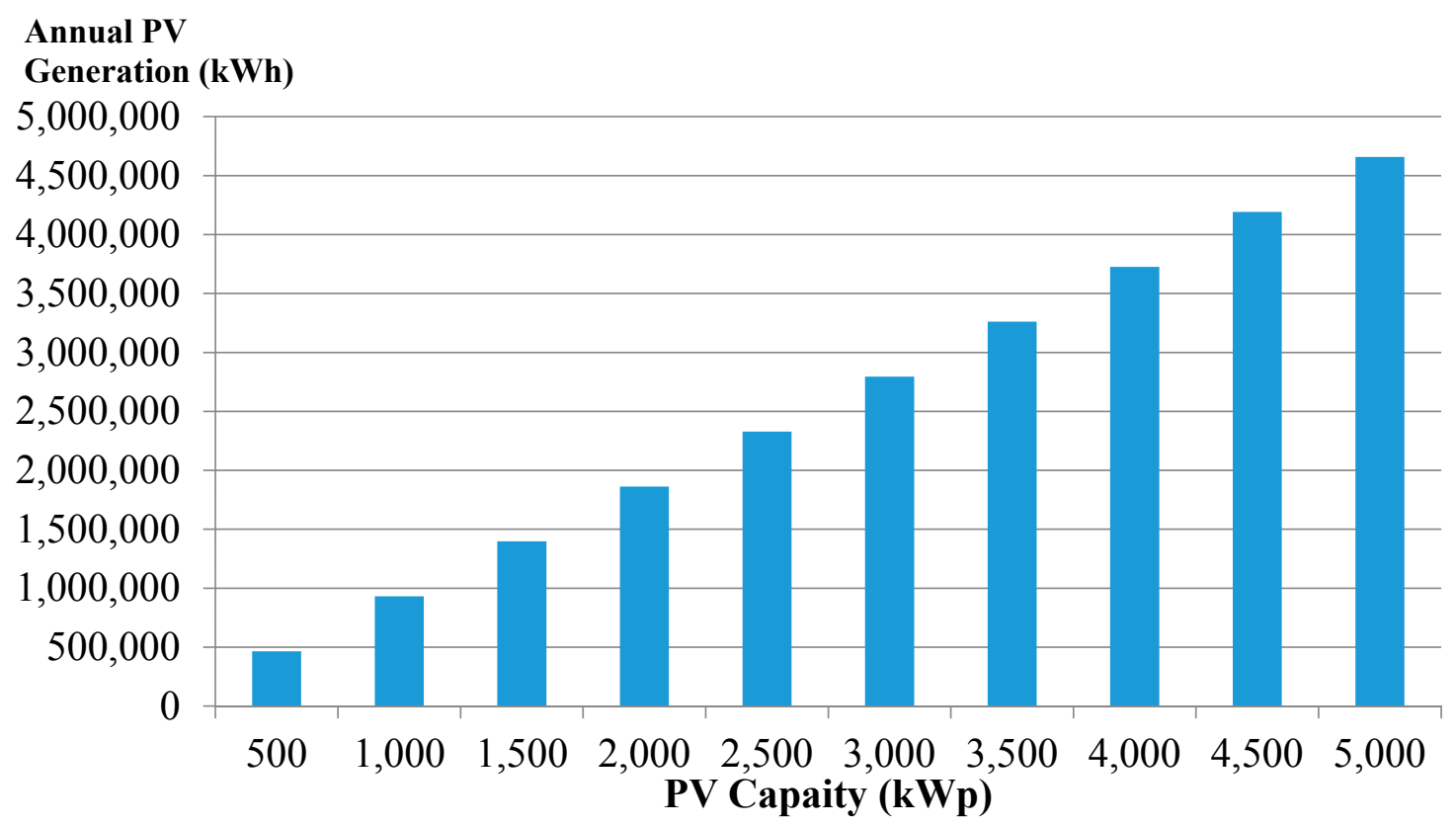

Figure 4. Annual PV real power generation (in kWh).

For the PV with fixed unity power factor $(p f=1.0)$, the annual PV generation, injection, and curtailment for PV capacity ranging from $500 \mathrm{kWp}$ to $5000 \mathrm{kWp}$ are drawn in Figure 5 . From Figure 5, it is shown that (1) the larger the PV capacity, the larger the annual power generation; (2) when the PV capacity exceeds $1500 \mathrm{kWp}$, the curtailment will rapidly increase and the actual power injection into the feeder will gradually increase and become flat.

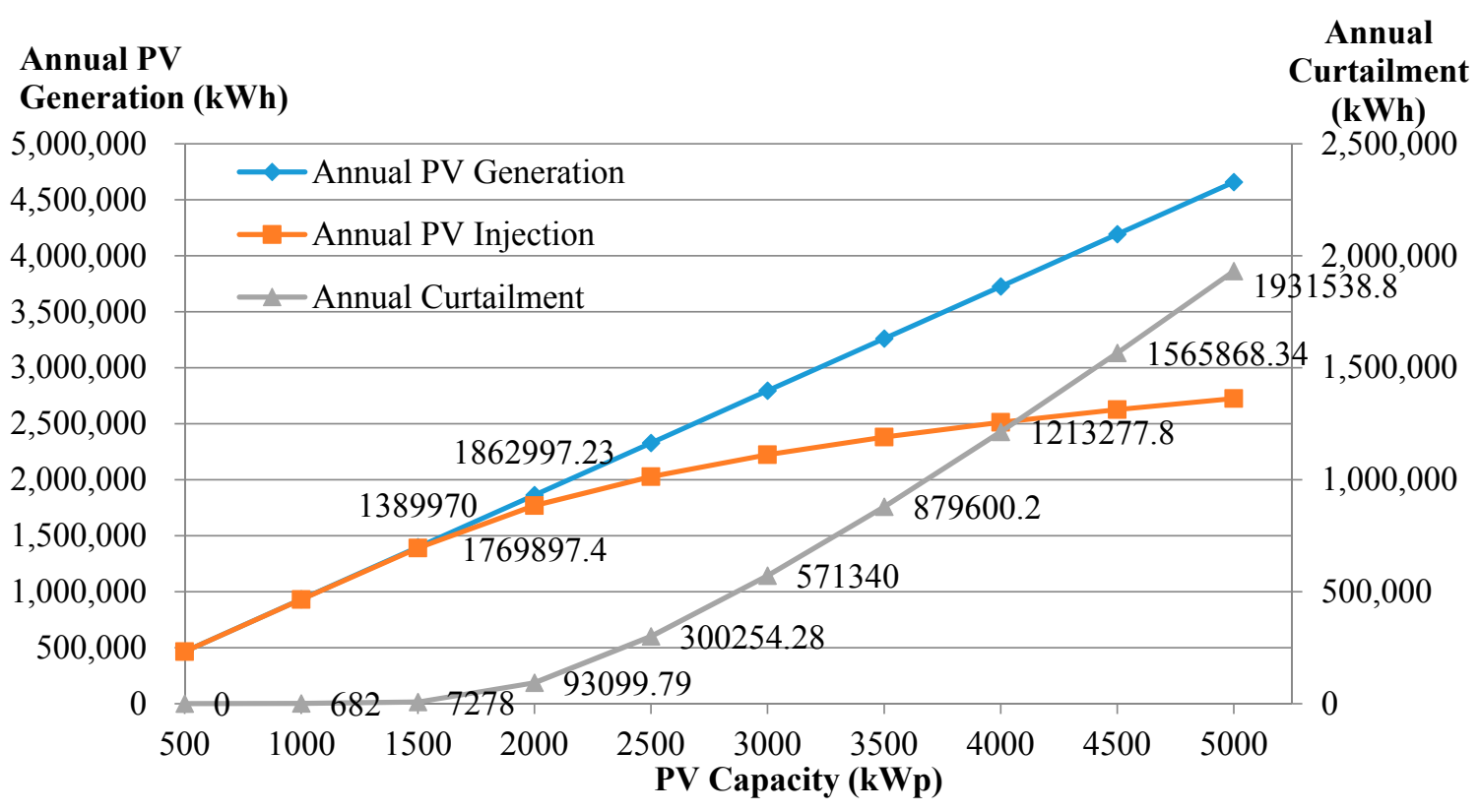

Figure 5. Annual PV generation, injection, and curtailment for different capacities $(p f=1.0)$. 


\subsection{The Maximal PV Real Power Injection for Different Power Factor Control Abilities}

Neglecting the period with very low level of irradiation, for load between 8:00 a.m. and 6:00 p.m., the maximal PV real power injection at each hour for different power factor control abilities is calculated based on the power flow program of OpenDSS and the real and reactive power control scheme of the smart PV inverter, and depicted in Figure 6.



Figure 6. Maximal PV real power injection for control abilities $p f=1.0,0.95,0.9$, and 0.85 .

From Figure 6, we can see that (1) the stronger the smart inverter's power factor control ability, the larger the allowable real power injection amount; that is, the PV installation capacity can also be increased; (2) the maximum real power injection for the power factor control abilities 0.9 and 0.85 are the same after 8 o'clock; that is, the smart PV inverter with more power factor control ability does not further increase the PV real power injection; thus, the smart PV inverter with power factor control ability $p f=0.9$ will be sufficient to play the role to increase the PV power injection to the feeder.

\subsection{Annual PV Real Power Injection for Different Power Factor Control Abilities}

The annual PV real power injection for different power factor control abilities are depicted in Figure 7. It can be seen from Figure 7 that (1) when the PV capacity is greater than $1500 \mathrm{kWp}$, the PV inverter with power factor control ability will exceed the PV without the ability to adjust power factor ( $p f=1.0$ ) in annual real power injection; (2) for PV capacity of $3500 \mathrm{kWp}$, the real power injection of PV with ability of power factor 0.9 or 0.85 is more than that of the PV with ability of power factor 0.95 ; (3) for PV inverters with the ability of power factor 0.9 and 0.85 , their annual real power injection are very close; thus, the smart PV inverter with power factor control ability $p f=0.9$ will be sufficient to play the role to increase the PV power injection to the distribution system. 


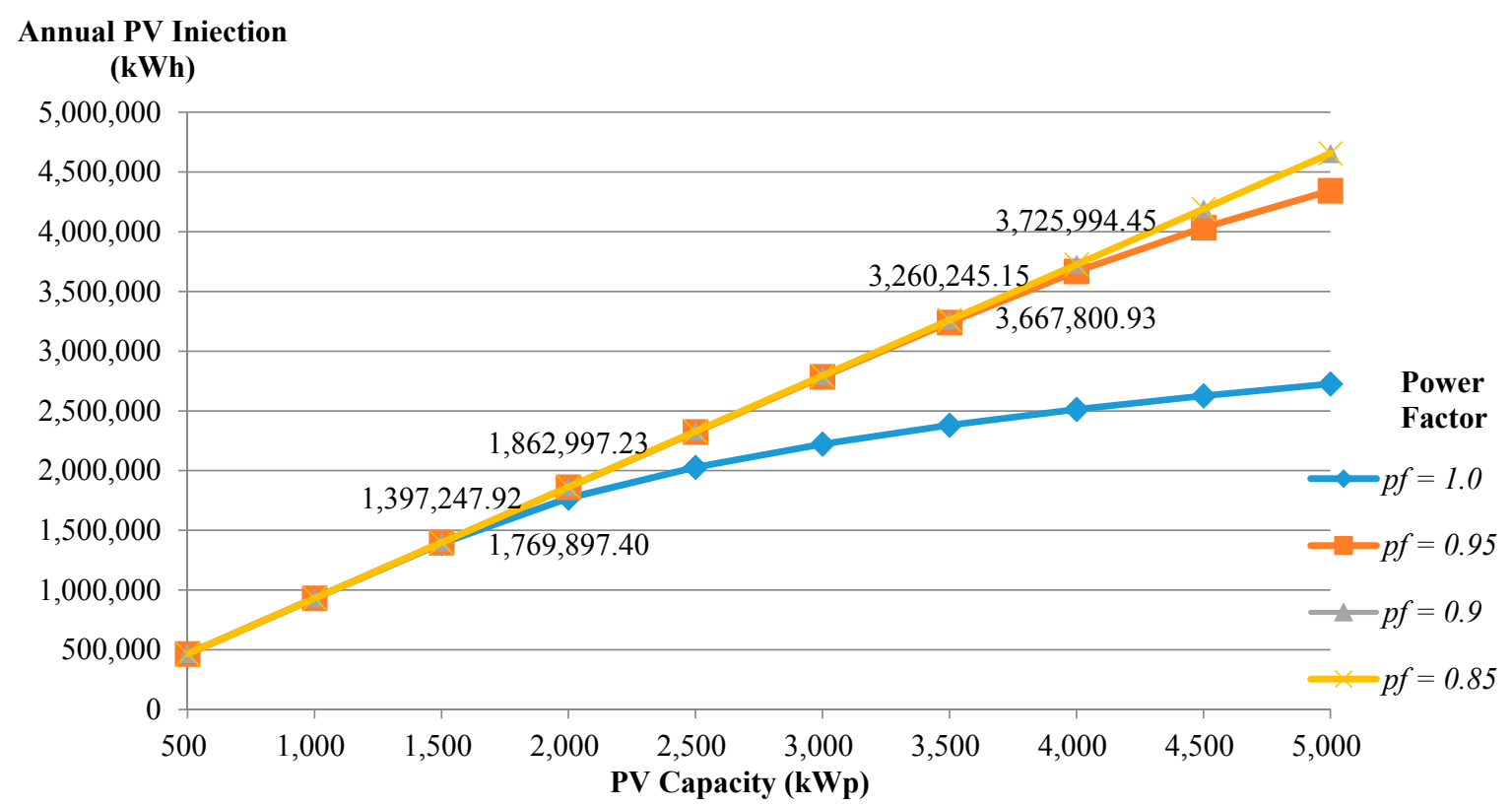

Figure 7. Annual PV real power injection for control abilities $p f=1.0,0.95,0.9$, and 0.85 .

\subsection{Annual PV Real Power Curtailment for Different Power Factor Control Abilities}

The annual PV real power curtailment, i.e., the total amount of PV power generation minus the actual injection in one year, is shown in Figure 8. If there is an energy storage system, we can take this curtailment as the annual amount for storage, but, in this paper, the energy storage system is not considered.

From Figure 8, it can be found that, in order not to exceed $2.5 \%$ voltage variation, the excess real power is curtailed, and the real power curtailed by power factor of 1.0 is the largest, followed by the power factor of 0.95 , and the third is the curtailment of $5321 \mathrm{kWh}$ for power factor of 0.9 . However, there is almost no curtailment for power factor of 0.9 or 0.85 . Therefore, the PV inverter with a power factor of 0.9 or 0.85 can improve the utilization of solar energy and seems to not require the installation of an energy storage system for excess PV power generation.



Figure 8. Annual PV real power curtailment for control abilities $p f=1.0,0.95,0.9$, and 0.85 . 


\section{Cost-Benefit Analysis for the Cases with or without Smart PV Inverters}

The NPVs and BCRs for PV inverters with different power factor control abilities are demonstrated in Figures 9 and 10.

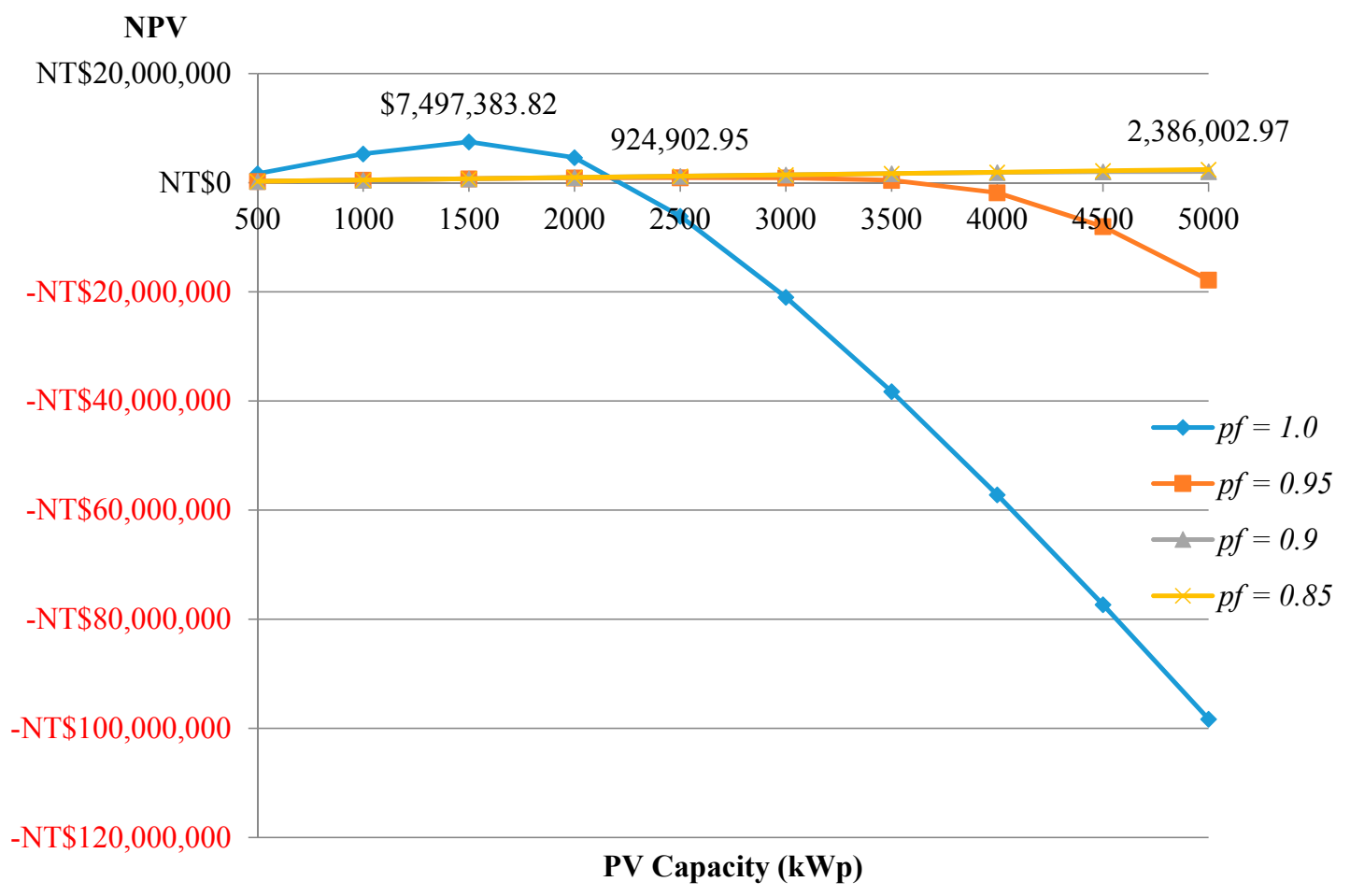

Figure 9. NPVs for control abilities $p f=1.0,0.95,0.9$, and 0.85; NPV: net present value.

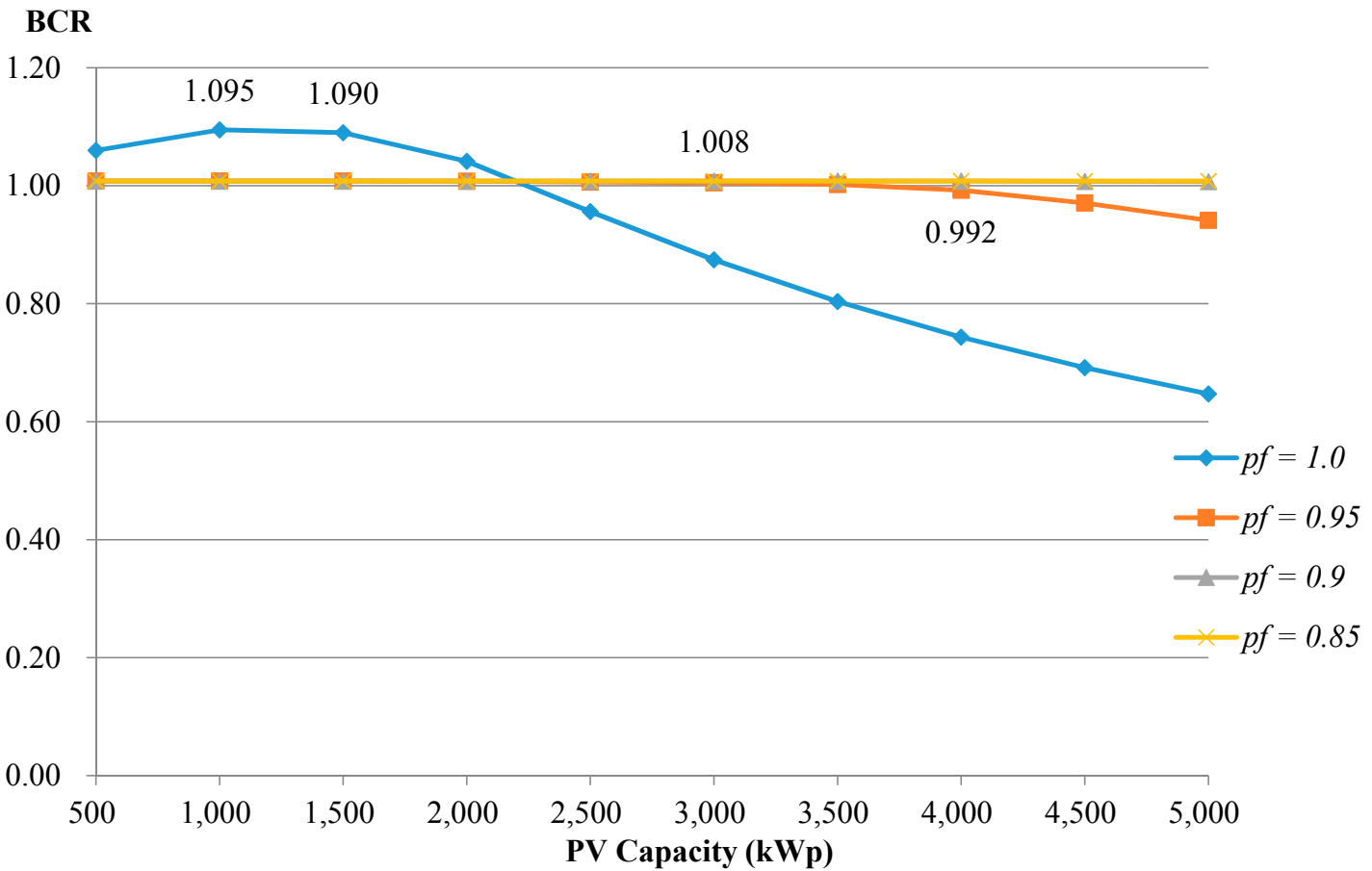

Figure 10. BCRs for control abilities $p f=1.0,0.95,0.9$, and 0.85 ; BCR: benefit-cost ratio. 
From Figures 9 and 10, it can be seen that (1) the highest NPV is around NT\$ 7.5 million with PV capacity of $1500 \mathrm{kWp}$, and the highest BCR is 1.095 with PV capacity of $1000 \mathrm{kWp}$; (2) when PV capacity is larger than $2200 \mathrm{kWp}$, the NPVs and BCRs for smart inverters are higher than that of normal inverter without reactive power control ability; (3) when PV capacity exceeds $3500 \mathrm{kWp}$, the NPVs and BCRs for those with control abilities $p f=0.9$ and 0.85 are greater than that with $p f=0.95$; (4) as the actual injection amounts for $p f=0.9$ and 0.85 are almost the same, the NPVs are very close and so are the BCRs; (5) since the reactive power compensation ability for $p f=0.9$ and 0.85 are very strong, even when PV capacity is high as $5000 \mathrm{kWp}$, the NPVs are still of no difference and so are the BCRs; hence, to analyze the difference between those with 0.9 and 0.85 power factors, the PV capacity must be larger than $5000 \mathrm{kWp}$, but it is out of the scope of Taiwan distribution system. In addition, for those with positive NPVs or with BCRs greater than 1, the maximal capacities of PV systems are around $2200 \mathrm{kWp}$ for $p f=1.0,3500 \mathrm{kWp}$ for $p f=0.95$, and above $5000 \mathrm{kWp}$ for $p f=0.9$ and 0.85 , respectively.

\section{Sensitivity Analysis for the Smart PV Inverters with Control Ability $p f=0.95$}

To handle project uncertainty, a sensitivity analysis is performed with respect to four key parameters: economic life, discount rate, FIT rate, and PV cost per $\mathrm{kWp}$. The de-rating rate of PV output and the percentage of PV cost for O\&M according to field experience are not performed. The system with a PV capacity of $2500 \mathrm{kWp}$ and control ability $p f=0.95$ is selected as the base case for sensitivity analysis.

The NPV and BCR sensitivity graphs as functions of percent deviation from the base case parameters are illustrated in Figures 11 and 12. As shown, based on the PV economic life of 20 years, the 3\% discount rate, the FIT of NT\$ $4.8845 / \mathrm{kWh}$, and the PV cost of NT\$ 56,350/kWp, the NPV and BCR sensitivities between $-50 \%$ and $+50 \%$ variations from each base parameter are demonstrated. For example, the NPVs are increased to NT\$ 77 million and NT\$ 36 million and decreased to NT\$ -16 million and NT\$ -74.75 million for a 50\% increase of FIT rate, economic life, discount rate, and PV cost, respectively. The BCRs are increased by $50 \%$ and $22.7 \%$ for a $50 \%$ increase of FIT rate and economic life, respectively, and are decreased by $11.2 \%$ and $33.3 \%$ for a $50 \%$ increase of discount rate and PV cost, respectively. It shows that the most sensitive parameter is the FIT rate, followed by the PV cost; the third is the economic life and the least sensitive parameter is the discount rate. Moreover, increase in the FIT rate and reduction in the PV cost will raise the values of NPV and BCR.

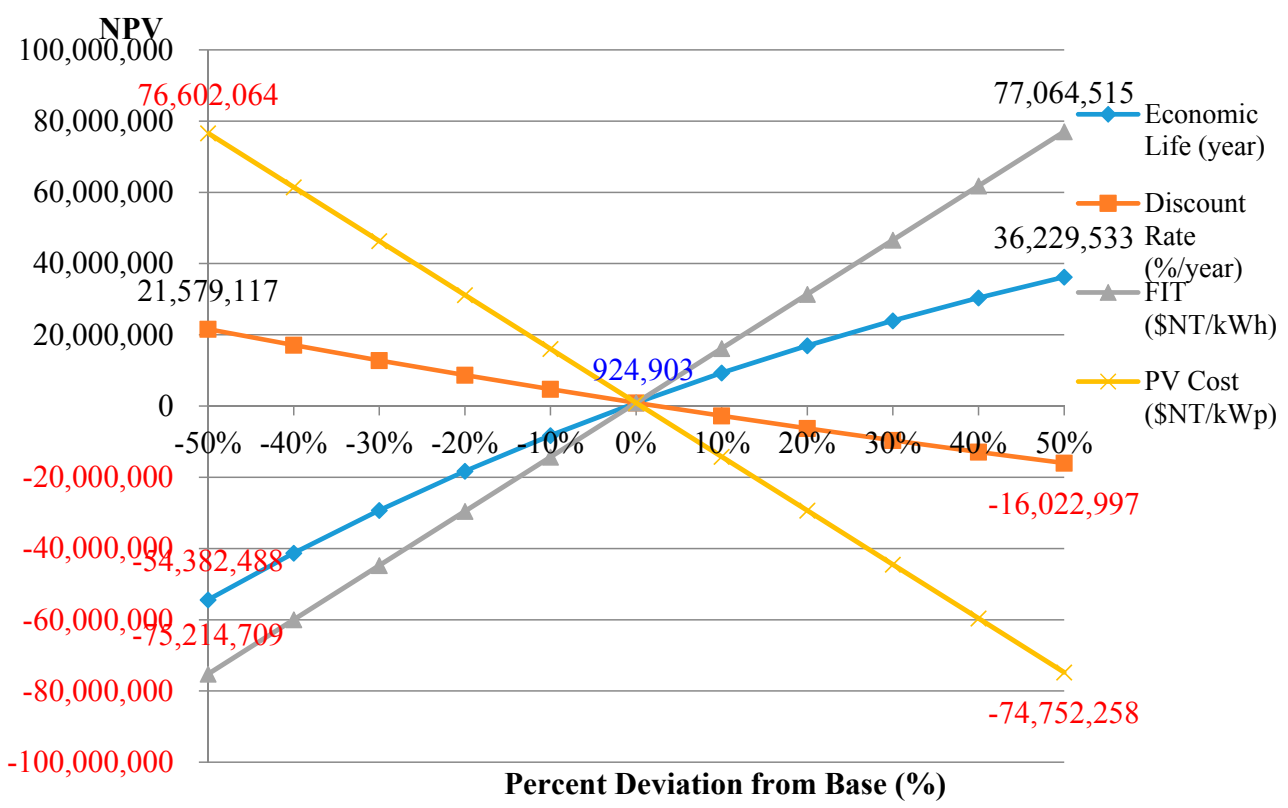

Figure 11. NPV sensitivity graph for four key parameters. 


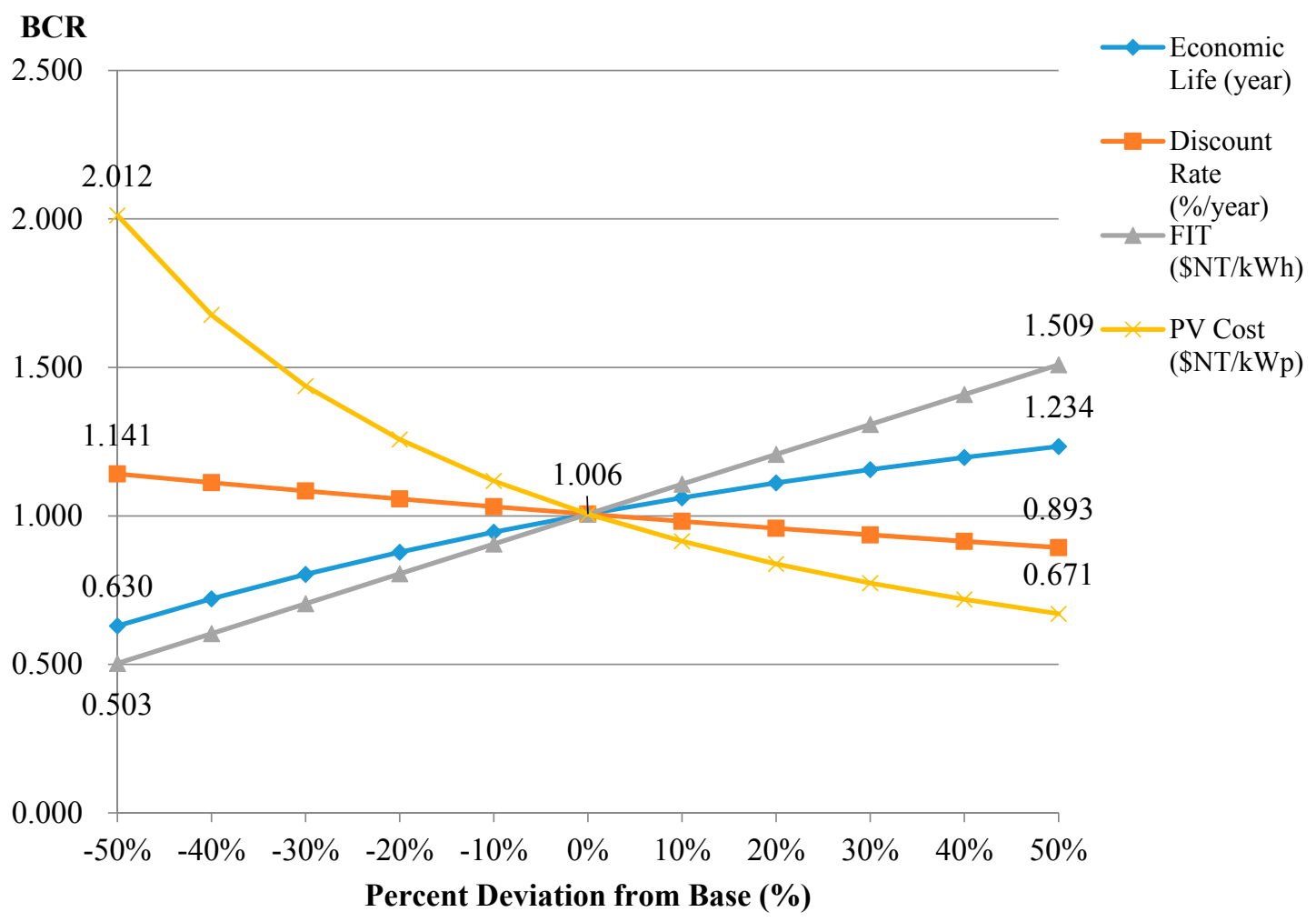

Figure 12. BCR sensitivity graph for four key parameters.

\section{Conclusions}

This paper has performed an economic evaluation of smart PV inverters with a three-operation-phase Watt-Var control scheme for enhancing PV penetration in distribution systems in Taiwan. The annual PV power injection and curtailment were estimated according to the annual duration curve of solar irradiation, and a Taipower distribution feeder was selected for economic evaluation. Some concluding remarks for the test feeder are listed as follows.

1. There is no need to have a smart inverter for the cases with PV capacities less than $1500 \mathrm{kWp}$ since their PV real power injection will not violate the voltage variation limit and no curtailment occurs.

2. When the PV capacity is greater than $1500 \mathrm{kWp}$, the smart PV inverter can enhance the injection of PV real power into the feeder and the utilization of PV power generation, and thus increase the PV grid-connected capacity in distribution feeders.

3. When the PV capacity is between $1500 \mathrm{kWp}$ and $3500 \mathrm{kWp}$, the smart PV inverter with control ability $p f=0.95$ will be sufficient to play the role to increase the PV power injection to the distribution system since there is almost no curtailment for $p f \leq 0.95$.

4. When the PV capacity is greater than $3500 \mathrm{kWp}$, the smart PV inverter with control ability $p f=0.9$ will be sufficient to play the role to increase the PV power injection to the distribution system since there is almost no curtailment for $p f \leq 0.9$.

5. According to the cost-benefit analysis, to gain a positive NPV or a BCR greater than 1, the maximal allowed PV capacities are around $2200 \mathrm{kWp}, 3500 \mathrm{kWp}$, and above $5000 \mathrm{kWp}$ for smart inverters with control ability $p f=1.0,0.95$, and 0.9 , respectively. That is, smart PV inverters with $p f \leq 0.95$ can increase the PV capacities by at least $59 \%$. This result may convince the Taiwan government to set a new standard on PV systems to have a smart inverter with power factor control ability of $p f \leq 0.95$ for enhancing PV penetration in distribution systems.

6. According to the sensitivity analysis, the NPV is increased to NT\$ 77 million for a FIT rate at NT\$ 7.3268/ kWh and to NT\$ 76.6 million for a PV cost at NT\$28,175. The BCRs are increased 
by $50 \%$ and $22.7 \%$, and decreased by $11.2 \%$ and $33.3 \%$ for a $50 \%$ increase of FIT rate, economic life, discount rate, and PV cost, respectively. That is, the most sensitive parameter is the FIT rate, followed by the PV cost; the third is the economic life and the least sensitive parameter is the discount rate. Moreover, increase in the FIT rate and reduction in the PV cost will raise the values of NPV and BCR.

Author Contributions: Conceptualization, S.-C.H.; Methodology, S.-C.H.; Formal Analysis, S.-C.H.; Writing-Original Draft Preparation, S.-C.H.; Writing-Review and Editing, S.-C.H.; Project Administration, Y.-D.L. and Y.-R.C.

Funding: This research was funded in part by the Ministry of Science and Technology of Taiwan, R.O.C., under Grants MOST 106-3113-E-214-001, MOST 106-2221-E-214-033, MOST 107-3113-E-214-001 and MOST 107-3113-E-042A-001-CC2.

Conflicts of Interest: The authors declare no conflict of interest. The founding sponsors had no role in the design of the study, in the collection, analyses, or interpretation of data, in the writing of the manuscript, and in the decision to publish the results.

\section{References}

1. Solar PV Two-Year Promotion Project, Bureau of Energy, Ministry of Economic Affairs, Taiwan. Available online: https:/ / www.moeaboe.gov.tw/ECW/english/content/Content.aspx?menu_id=5492 (accessed on 19 May 2018).

2. Interconnection Standard for Renewable Energy Generation in Taipower, Taiwan Power Company. Available online: http:/ / www.taipower.com.tw/left_bar/rules_item/Regeneration_energy.htm (accessed on 29 November 2010).

3. Global Market Outlook for Photovoltaics 2014-2018, European Photovoltaic Industry Association. Available online: https:/ / resources.solarbusinesshub.com/solar-industry-reports/item/global-market-outlookfor-photovoltaics-2014-2018 (accessed on 3 June 2018).

4. Manju, S.; Sagar, N. Progressing towards the development of sustainable energy: A critical review on the current status, applications, developmental barriers and prospects of solar photovoltaic systems in India. Renew. Sustain. Energy Rev. 2017, 70, 298-313. [CrossRef]

5. Carrasco, J.M.; Franquelo, L.G.; Bialasiewicz, J.T.; Galván, E.; PortilloGuisado, R.C.; Prats, M.M.; León, J.I.; Moreno-Alfonso, N. Power-electronic systems for the grid integration of renewable energy sources: A survey. IEEE Trans. Ind. Electron. 2006, 53, 1002-1016. [CrossRef]

6. Spertino, F.; Graditi, G. Power conditioning units in grid-connected photovoltaic systems: A comparison with different technologies and wide range of power ratings. Sol. Energy 2014, 108, 219-229. [CrossRef]

7. Vasquez, J.C.; Mastromauro, R.A.; Guerrero, J.M.; Liserre, M. Voltage support provided by a droop-controlled multifunctional inverter. IEEE Trans. Ind. Electron. 2009, 56, 4510-4519. [CrossRef]

8. Bollen, M.H.J.; Sannino, A. Voltage control with inverter-based distributed generation. IEEE Trans. Power Deliv. 2005, 20, 519-520. [CrossRef]

9. Carvalho, P.M.S.; Correia, P.F.; Ferreira, L.A.F. Distributed reactive power generation control for voltage rise mitigation in distribution networks. IEEE Trans. Power Syst. 2008, 23, 766-772. [CrossRef]

10. Chen, C.S.; Lin, C.H.W.; Hsieh, L.; Hsu, C.T.; Ku, T.T. Enhancement of PV penetration with DSTATCOM in Taipower distribution system. IEEE Trans. Power Syst. 2013, 28, 1560-1567. [CrossRef]

11. Mahmud, N.; Zahedi, A.; Mahmud, A.A. A cooperative operation of novel PV inverter control scheme and storage energy management system based on ANFIS for voltage regulation of grid-tied PV system. IEEE Trans. Ind. Inf. 2017, 13, 2657-2668. [CrossRef]

12. Smith, J. Modeling High-Penetration PV for Distribution Interconnection Studies: Smart Inverter Function Modeling in OpenDSS, Rev. 2; EPRI: Palo Alto, CA, USA, 2013.

13. Howlader, A.M.; Sadoyama, S.; Roose, L.R.; Sepasi, S. Distributed voltage regulation using Volt-Var controls of a smart PV inverter in a smart grid: An experimental study. Renew. Energy 2018, 127, 145-157. [CrossRef]

14. Ku, T.T.; Lin, C.H.; Chen, C.S.; Hsu, C.T.; Hsieh, W.L.; Hsieh, S.C. Coordination of PV inverters to mitigate voltage violation for load transfer between distribution feeders with high penetration of PV installation. IEEE Trans. Ind. Appl. 2016, 52, 1167-1174. [CrossRef]

15. Cucchiella, F.; D'Adamo, I.; Gastaldi, M. The economic feasibility of residential energy storage combined with PV panels: The Role of subsidies in Italy. Energies 2017, 10, 1434. [CrossRef] 
16. Hsieh, S.C. Economic evaluation of the hybrid enhancing scheme with DSTATCOM and active power curtailment for PV penetration in Taipower distribution systems. IEEE Trans. Ind. Appl. 2015, 51, 1953-1961. [CrossRef]

17. Simulation Tool-OpenDSS, EPRI. Available online: http://smartgrid.epri.com/SimulationTool.aspx (accessed on 20 May 2018).

18. Park, C.S. Contemporary Engineering Economics, 3rd ed.; Prentice-Hall: Englewood Cliffs, NJ, USA, 2002.

19. Million Solar Rooftop PVs and Annual Report, Bureau of Energy, Ministry of Economic Affairs, Taiwan. Available online: http:/ / web3.moeaboe.gov.tw/ECW/english/content/SubMenu.aspx?menu_id=1832 (accessed on 20 July 2015).

20. Solar Choice. Available online: http:/ / www.solarchoice.net.au/blog/solar-choice-pv-price-index-march2013/ (accessed on 30 May 2013).

21. T\&DWorld. Available online: http://tdworld.com/generation-renewables/smart-inverters-worth-cost (accessed on 22 April 2018).

(C) 2018 by the authors. Licensee MDPI, Basel, Switzerland. This article is an open access article distributed under the terms and conditions of the Creative Commons Attribution (CC BY) license (http:// creativecommons.org/licenses/by/4.0/). 